\title{
PREDATOR-AVOIDANCE BEHAVIOR EXTENDS TROPHIC CASCADES TO REFUGE HABITATS
}

\author{
Jonathan H. GRABOWSKI ${ }^{1,3}$ AND DAVID L. KIMBRO ${ }^{2}$ \\ ${ }^{1}$ University of North Carolina at Chapel Hill, Institute of Marine Sciences, Morehead City, North Carolina 28557 USA \\ ${ }^{2}$ University of California, Department of Environmental Science and Policy, Davis, California 95616 USA
}

\begin{abstract}
Consideration of how trait-mediated indirect interactions (TMIIs) affect community dynamics is recognized as an important focus for ecological research. Although these indirect effects have been shown to mediate trophic cascades in ecological communities, our understanding of how habitat refuge influences the strength and direction of cascading effects is limited. We examined whether or not oyster toadfish (top predator) affect mud crab (intermediate predator) foraging on juvenile hard clams (infaunal prey) in oyster reefs, a physically complex habitat that can provide refuge for both intermediate predators and basal prey. In particular, we manipulated toadfish presence in mesocosms containing experimental oyster reefs and quantified both mud crab and juvenile clam mortality. Toadfish significantly reduced mud crab foraging on clams and increased clam survivorship even though mud crabs foraging on the surface of the reef sought refuge from toadfish deeper within the oyster-shell matrix where they were more proximal to clams. This counterintuitive result suggests that toadfish suppression of mud crab foraging activity is far stronger than toadfish-avoidance behavior that potentially increases crab-clam encounter rates. Therefore, TMIIs can reinforce trophic cascades even in refuge habitats where intermediate predators and their prey are physically isolated from top predators. Determining the generality of cascading effects on lower trophic levels within refugia will require investigating how habitat refuge affects the relative importance of TMIIs.
\end{abstract}

Key words: density-mediated indirect interactions (DMIIs); habitat complexity; habitat refuge; mesocosm experiment; mud crabs; oyster reefs; predator-avoidance behavior; prey switching; toadfish; trait-mediated indirect interactions (TMIIs); trophic cascades.

\section{INTRODUCTION}

Predators can profoundly shape the ecology and evolution of prey populations (Hairston et al. 1960, MacArthur and Levins 1967, Connell 1980, Carpenter et al. 1985). In addition to the well-documented direct effects of predation, the indirect effects of predatorprey interactions have been speculated to be as important, if not more so, than the direct effects in structuring communities (Hairston et al. 1960, Paine 1966, Power et al. 1985, Wootton 1993, Menge 1995). For instance, trophic cascades, in which a top predator indirectly benefits basal prey via its effects on an intermediate predator, have been documented in a wide diversity of systems and are particularly strong in freshwater and marine benthic communities (Carpenter et al. 1985, Strong 1992, Shurin et al. 2002). Animal behavior can also influence interactions among competitors or predators and their prey, and subsequently affect the strength of trophic cascades (Luttbeg et al. 2003, Werner and Peacor 2003).

Manuscript received 2 August 2004; revised 11 October 2004; accepted 14 October 2004. Corresponding Editor: O. J. Schmitz.

${ }^{3}$ Present address: Gulf of Maine Research Institute, 350 Commercial Street, Portland, Maine 04101 USA.

E-mail: jgrabowski@gmri.org
Trait-mediated indirect interactions (TMIIs) among species affect community dynamics within terrestrial and aquatic systems via several mechanisms, including prey switching, starvation, and emigration. Predators induce changes in prey foraging patterns that modify predation rates on alternative basal prey and potentially shift community structure (Power et al. 1985). Exposure of prey to non-lethal predators can reduce prey growth and survivorship, presumably through starvation (Werner and Anholt 1996). Predator risk may also control emigration rates of intermediate predators and prey (Forrester 1994), which could influence food-web interactions within recipient communities (Polis et al. 1997, Nakano et al. 1999). Consequently, the mere presence of a top predator may be more important than the removal of intermediate predators as a determinant of community structure (Werner and Peacor 2003, Schmitz et al. 2004). Yet studies that simultaneously assess the relative strength and spatial extent of TMIIs in community dynamics are scarce (Werner and Peacor 2003), especially within marine systems (Dill et al. 2003). Determination of whether intermediate predators, when driven into refugia, initiate trophic cascades within these structured habitats will provide a more comprehensive understanding of how TMIIs influence trophic cascades and community composition. 
Habitat complexity creates refuge for lower trophic levels by reducing predator efficiency, explaining why these refuge habitats often support dense assemblages of prey (Crowder and Cooper 1982). Thus, the existence of habitat refugia can disrupt predator-prey interactions and subsequently attenuate the strength of density-mediated indirect interactions (DMIIs) (Werner and Peacor 2003). When intermediate predators seek refuge in response to top predators, this behavioral effect can initiate cascading TMIIs within refuge habitats if intermediate predators shift to foraging predominately within the refuge habitat. For instance, Schmitz (1998) demonstrated that when terrestrial herbivores relocate to safer plant species, top predators have a negative indirect effect on these plant species that create refuge. Alternatively, intermediate predators that seek shelter within a refuge habitat may continue to respond to the risk of predation by reducing foraging activity. In this scenario, the TMII would continue to have a net positive effect on prey within the refuge habitat because predator avoidance behavior would extend within the sheltered habitat. Although both alternatives predict that TMIIs should be much stronger than DMIIs and consequently structure communities within refuge habitats, the net outcome of top predators on basal prey within refugia depends upon the behavioral responses of intermediate predators.

Oyster reefs are biogenic habitats that create physical complexity and vertical relief as each new generation of oysters settles on the foundation created by previous generations. The resultant reef habitat is a complex shell matrix that supports dense assemblages of sessile and mobile invertebrates (Arve 1960, Wells 1961, Coen et al. 1999, Lenihan et al. 2001). Mud crabs (Panopeus herbstii), a prevalent intermediate predator on oyster reefs, utilize this prey-rich habitat as refuge and foraging grounds. Mud crabs have been shown to be important consumers of juvenile oysters (Crassostrea virginica) (McDermott and Flower 1952) and ribbed mussels (Geukensia demissa) (Seed 1980) on the surface of the reef as well as of juvenile hard clams (Mercenaria mercenaria) within the shell matrix and in adjacent mud bottom (Whetstone and Eversole 1978, Micheli and Peterson 1999, Grabowski and Powers 2004). MacDonald (1940) and McDermott and Flower (1952) found that mud crabs prefer oysters, while Silliman et al. (2004) found that mud crab foraging patterns are proportional to local prey densities. Mud crabs should forage more effectively on juvenile oysters in the absence of crab predators because they are often extremely dense $\left(\right.$ mean $=14667$ oysters $/ \mathrm{m}^{2}$; Bahr and Lanier 1981) on the surface of the reef where reduced complexity should increase crab foraging efficiency by reducing prey search time. On the contrary, juvenile hard clams and other subsurface bivalves are at much lower densities $\left(\right.$ mean $=284$ non-oyster bivalves $/ \mathrm{m}^{2}$; Grabowski 2002) than oysters and are imbedded between sediments and shell material below the surface of the reef, which should reduce mud crab foraging efficiency. The oyster toadfish (Opsanus tau) is a common consumer of mud crabs (Schwartz and Dutcher 1963, Wilson et al. 1982) that reduces mud crab consumption of juvenile oysters on oyster reefs (Grabowski 2004). Toadfish indirectly benefit juvenile oysters primarily by inducing mud crabs foraging on the surface of the reef to seek shelter within the shell matrix, thereby potentially influencing interactions among mud crabs and other prey species.

In this study, we experimentally tested if toadfish influence mud crab foraging on alternative prey in a refuge habitat. More specifically, we manipulated toadfish presence and quantified mud crab consumption of juvenile hard clams. We predicted that the threat of toadfish predation could result in mud crabs consuming more juvenile hard clams if toadfish-avoidance behavior (i.e., relocating deeper within the shell matrix) increases encounter rates between mud crabs and hard clams (Fig. 1). Thus, toadfish may induce mud crabs to switch from foraging on juvenile oysters near the surface of the reef to juvenile hard clams within the interstices of the reef. Alternatively, toadfish could indirectly benefit juvenile hard clams if the presence of toadfish reduces mud crab foraging on all prey. In such a scenario, reductions in mud crab foraging by toadfish would outweigh movement of mud crabs deeper within the shell matrix and closer to infaunal prey. Toadfish would therefore be indirectly benefiting both exposed prey on the surface and sheltered prey within the reef because the trophic cascade would pervade even within the habitat shelter where toadfish are not effective foragers on mud crabs. A third possibility is that toadfish simply reduce the number of mud crabs by direct consumption, resulting in fewer mud crabs and less predation on oysters and clams. We manipulated top-predator presence and observed mud crab migratory behavior to determine how DMIIs and TMIIs affect trophic cascades within refuge habitats.

\section{Materials and Methods}

We conducted a mesocosm experiment at the University of North Carolina-Institute of Marine Sciences laboratory in Morehead City, North Carolina, USA, in the fall of 1999 to test how toadfish affect mud crab consumption of juvenile hard clams. We submerged twelve cylindrical, plastic pools $(1.7 \mathrm{~m}$ wide $\times 0.3 \mathrm{~m}$ tall) within a concrete tank $(6 \times 9 \times 1.2 \mathrm{~m})$ that was continuously pumped with unfiltered seawater from Bogue Sound, North Carolina (0.27-0.29 1/s), maintaining a constant depth of $1.2 \mathrm{~m}$. Each individual pool was enclosed with a 6-mm mesh plastic fence that extended from the top of the pool to $20 \mathrm{~cm}$ above the water surface. Mesocosms were covered with 10-mm mesh bird netting to prevent fish and crabs from escaping.

We manipulated toadfish presence and quantified both mud crab and juvenile clam mortality. Before con- 
a)

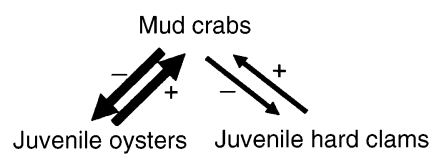

Trait-mediated effects

c) Scenario 1: Prey switching

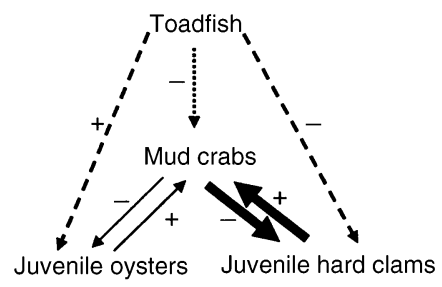

d) Scenario 2: Crab vigilance

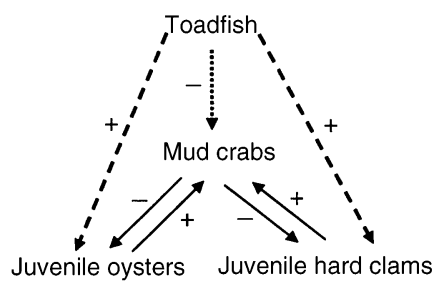

FIG. 1. Hypothesized indirect effects of toadfish on juvenile oysters and hard clams as a consequence of the influences of toadfish consumption of mud crabs (density-mediated) and toadfish modifications of mud crab behavior (trait-mediated) on mud crab-prey interactions. Solid lines indicate direct trophic interactions, dotted lines indicate direct behavioral modifications of mud crabs induced by toadfish, and dashed lines indicate a net indirect effect of toadfish on juvenile prey propagated by either a density- or trait-mediated interaction with mud crabs. Arrows indicate the direction and strength (arrow thickness) of the interaction among species pairs, and the sign indicates the net outcome. (a) Mud crabs forage on both prey species but predominately on juvenile oysters in the absence of toadfish predators. (b) Toadfish consume mud crabs, thereby reducing mud crab consumption of both prey species. (c) Toadfish induce mud crabs to forage deeper within the reef, in greater proximity to juvenile hard clams, thereby inducing mud crabs to consume more juvenile hard clams than in the absence of toadfish. (d) Under this alternative scenario, increased mud crab vigilance in the presence of toadfish results in reduced mud crab foraging on juvenile hard clams. structing experimental reefs, 40 juvenile hard clams $(13.2 \pm 0.2 \mathrm{~mm}$ shell length [mean $\pm 1 \mathrm{sE}$ ]) were systematically dispersed in the sediments in between the shell and sand using a $0.25-\mathrm{m}^{2}$ gridded quadrat centered within each cylindrical pool. We then constructed $\mathrm{a} \sim 2-\mathrm{m}^{2}$ reef within each of the 12 pools by depositing twenty gallons of individual oyster shells. Oyster shells were placed on the sediment layer individually to avoid increasing clam mortality rates. Constructed reefs contained the vertical relief and physical complexity of shallow subtidal and intertidal natural oyster reefs, which typically extend upward off the bottom $10-50 \mathrm{~cm}$ in North Carolina. Clams were given 24 hours to adjust after adding sea water to the settling tank. Thirty mud crabs were placed in each pool, after which we added one toadfish to each of six randomly selected pools. Previous mesocosm experiments in this settling tank have demonstrated that mesocosms enclose all predators (Grabowski 2004). Preliminary trials determined that clam mortality rates are extremely low (i.e., $<2 \%$ ) in the absence of crab predators (J. H. Grabowski, unpublished data).

After six days the settling tank was drained in order to quantify mud crab and clam mortality. All shell and sediment material from beneath the oyster reef was sieved to maximize recovery of living and dead clams and mud crabs. We analyzed whether toadfish affected mud crab and juvenile hard clam survivorship using separate unpaired $t$ tests. Only juvenile hard clam data required arcsine transformation to reduce heteroscedasticity (Underwood 1981).

In addition to quantifying mud crab and clam survivorship, we calculated crab consumption rates of clams in order to partition the indirect effects of toadfish (direct removal of crabs vs. altered foraging activity) on clam survivorship (Grabowski 2004). Mud crab consumption rates of clams were quantified by determining the average number of clams eaten by crabs during the experimental trial and dividing it by the average number of crabs present during the experimental run. We analyzed if toadfish influence mud crab foraging rates with an unpaired $t$ test. Toadfish effects on clams then were partitioned between direct removal of crabs by toadfish (density-mediated indirect interaction, DMIIs) and altered foraging behavior of crabs (trait-mediated indirect interactions, TMIIs).

Because toadfish indirectly benefited clams in this experiment, we calculated the actual number of clams released from mud crab predation when toadfish were present. Specifically, we subtracted the number of clams consumed by mud crabs with toadfish present from the number consumed by mud crabs in the absence of toadfish (actual release $=$ direct removal and altered foraging behavior). We estimated how the direct removal of mud crabs (DMII) affects clam survivorship by determining the expected number of clams that should have been released from mud crab predation as a consequence of toadfish consuming mud crabs and lowering their densities (number of clams consumed per crab in the absence of toadfish multiplied by the average number of crabs consumed by toadfish during an experimental run). Using expected vs. actual clam release, we quantified the proportion of clams released from mud crab predation as a result of toadfish removal of mud crabs (DMII: expected/actual clam release) vs. from altered mud crab foraging behavior in the pres- 
ence of toadfish (TMII: [actual - expected]/actual clam release).

To determine if toadfish affect mud crab mobility within and around oyster reefs, a series of behavioral observations were conducted in the experimental tank setting described above in the fall of 1997. In addition to observing mud crab presence on the shell surface of experimental oyster reefs (see Grabowski 2004), mud crab movement was quantified in a subsequent trial. In order to conduct observations in the evening, phosphorescent stars (Star Glows [Illuminations, Derry, New Hampshire, USA]) were attached to the carapace of all mud crabs used in this experiment. Forty mud crabs with stars were added to each of eight pools (four with vs. four without toadfish) containing $\sim 2-\mathrm{m}^{2}$ experimental oyster reefs with juvenile oysters and crushed mussels. Behavioral observations were conducted in the evening when mud crabs typically are more active, for six consecutive days. The number of moving crabs was quantified after illuminating each pool with a $50-\mathrm{cm}$ fluorescent light for $15 \mathrm{~s}$ every 10 min for $1 \mathrm{~h}$ during each night of the six-day trial. Each pool was observed for $30 \mathrm{~s}$ after it was illuminated to quantify the number of crabs that moved at least $5 \mathrm{~cm}$ during the observation period. All seven observations during each 1-h sampling period were averaged to obtain an estimate of the number of mobile crabs observed in each pool during the observational hour.

Because toadfish consumed mud crabs in the four toadfish-containing pools, crab observations were standardized by dividing the total number of mobile crabs by the average crab density within each pool to account for differences in mud crab mortality. A one-way repeated-measures ANOVA was conducted on the effect of toadfish on the total number of mobile crabs. Toadfish greatly reduced the number of visible crabs in comparison to pools without toadfish. Therefore, the number of mobile crabs was divided by the total number of visible crabs in each pool during each sampling period to account for differences in the number of visible crabs in each treatment. We conducted a second repeated-measures ANOVA on the effect of toadfish on the proportion of visible crabs that were mobile. For each analysis, Cochran's test for homogeneity of variance was conducted on all main effects (Underwood 1981). Because neither analysis violated the assumption of homogeneous variances, Student-NewmanKeuls (SNK) post hoc tests were conducted for all significant interaction terms and main effects with more than two levels (i.e., experimental day) (Day and Quinn 1989).

\section{RESULTS}

Toadfish did not significantly affect mud crab mortality. There was a slight trend of reduced mud crab survivorship in the presence of toadfish $(t=1.94$, df $=10, P=0.081)$. However, mud crab survivorship was consistently high (Fig. 2a), and toadfish reduced
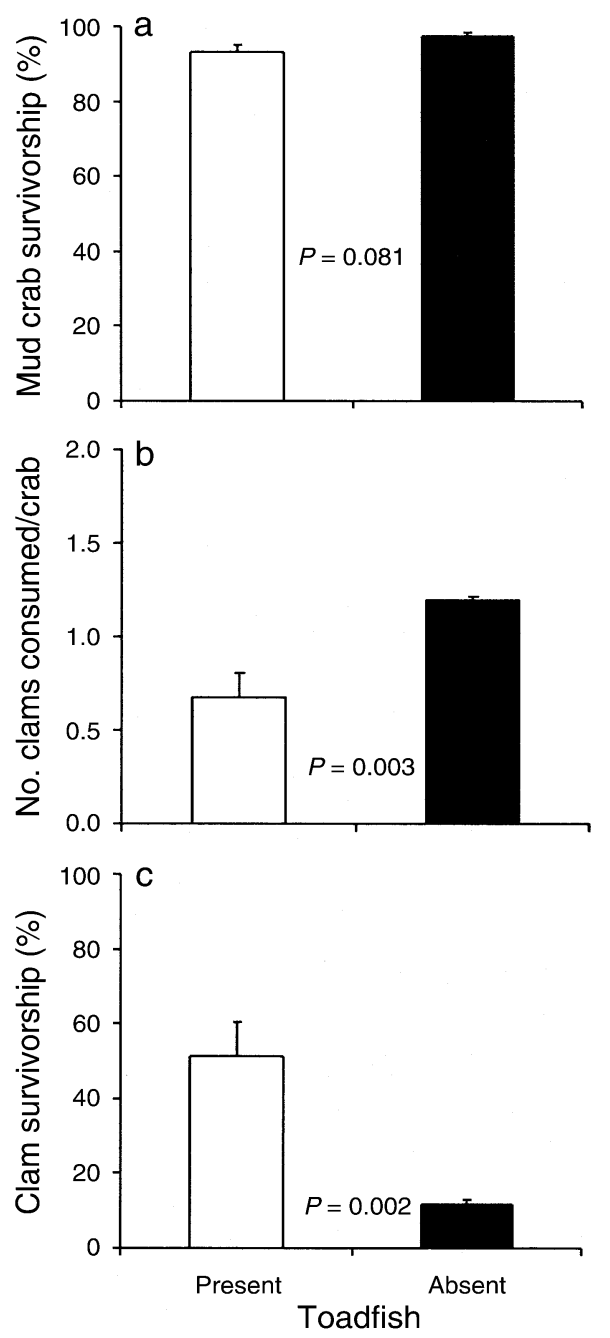

FIG. 2. (a) Mud crab survival, (b) mud crab foraging rate, and (c) juvenile hard clam survival within oyster reefs in the presence vs. the absence of toadfish. Data are means and 1 SE; $n=6$ replicates. The $P$ values presented are the results of unpaired $t$ tests. Toadfish significantly reduced clam survivorship by decreasing mud crab foraging within oyster reefs.

mud crab survivorship by only $3.9 \%$. Toadfish reduced crab foraging rates by $43.6 \%$ during the experiment $(t=3.97$, df $=10, P=0.003$; Fig. 2b), and significantly increased clam survivorship by $39.6 \%(t=4.27$, df $=10, P=0.002$; Fig. 2c).

Partitioning of the indirect effects (direct removal of crabs vs. predator-avoidance behavior) of toadfish on juvenile clams determined that trait-mediated indirect interactions (TMIIs) accounted for $87.7 \%$ of the benefit to clams (Table 1). Prey depletion occurred in mesocosms without toadfish, so that mud crab consumption of clams in the absence of toadfish is probably underestimated. Therefore, TMIIs are likely larger than approximated in this study because even greater mud crab consumption of clams would have occurred in the ab- 
TABLE 1. Partitioning the toadfish effects (direct removal of mud crabs [density-mediated] vs. reduced crab foraging activity [trait-mediated]) on the daily rates of clam mortality induced by mud crabs (i.e., mud crab foraging rates).

\begin{tabular}{|c|c|c|c|c|c|}
\hline \multirow{3}{*}{$\begin{array}{l}\text { Toadfish } \\
\text { presence }\end{array}$} & \multirow{3}{*}{$\begin{array}{c}\text { Mud crab } \\
\text { feeding rate } \\
\left(\text { clams } \cdot \text { crab }^{-1} \cdot \mathrm{d}^{-1}\right) \dagger\end{array}$} & & & \multicolumn{2}{|c|}{ Toadfish effect } \\
\hline & & \multicolumn{2}{|c|}{$\begin{array}{l}\text { Clam release } \\
\text { (no. clams/d) }\end{array}$} & \multirow{2}{*}{$\begin{array}{l}\text { 1) Removal of crabs, } \\
\text { DMII; (expected/ } \\
\text { actual clam release) } \|\end{array}$} & \multirow{2}{*}{$\begin{array}{l}\text { 2) Mud crab behavioral } \\
\text { change, TMII; } \\
\text { ([actual - expected]/ } \\
\text { actual clam release)I }\end{array}$} \\
\hline & & Expected $\ddagger$ & Actual§ & & \\
\hline \multicolumn{6}{|l|}{ This study } \\
\hline No toadfish & $1.19(0.02)$ & & & & \\
\hline Toadfish & $0.67(0.13)$ & $1.20(0.32)$ & $15.83(3.68)$ & $12.3 \%(6.0 \%)$ & $87.7 \%(6.0 \%)$ \\
\hline \multicolumn{6}{|l|}{ Corrected } \\
\hline No toadfish & $4.27(0.49)$ & & & & \\
\hline Toadfish & $0.67(0.13)$ & $4.61(1.59)$ & $108.50(14.89)$ & $4.0 \%(1.0 \%)$ & $96.0 \%(1.0 \%)$ \\
\hline
\end{tabular}

Notes: DMII = density-mediated indirect interaction; TMII = trait-mediated indirect interaction. Because prey depletion may have resulted in underestimated values of TMIIs in this study, estimates were corrected using crab foraging rates on juvenile hard clams from a similar study in which prey depletion did not occur (Grabowski and Powers 2004). Data are means with $1 \mathrm{SE}$ in parentheses.

$\dagger$ Mud crab feeding rate is the average number of clams consumed per crab present per day during an experimental run.

\$ Expected clam release estimates the expected decrease in the average number of clams consumed per day by mud crabs as a function of lowered crab densities in the presence of fish. Expected clam release is calculated by multiplying the daily rate of crab removal of clams (i.e., mud crab foraging rate) in the absence of fish by the reduction in crab density induced by toadfish during an experimental run.

$\S$ Actual clam release calculations measure the actual number of clams per day released from mud crab predation in the presence of toadfish. Actual release is calculated by subtracting the number of clams consumed by mud crabs with toadfish present from the number consumed by mud crabs in the absence of toadfish.

$\|$ The percentage of toadfish indirect effects on clam mortality explained by toadfish removal of mud crabs.

II The percentage of toadfish indirect effects on clam mortality explained by toadfish-induced modifications in mud crab foraging behavior.

sence of toadfish relative to crab foraging rates in the presence of toadfish given the higher initial starting densities of clams. Recalculation of TMIIs, using crab foraging rates on juvenile hard clams in the absence of toadfish from a similar mesocosm experiment in which depletion did not occur (Grabowski and Powers 2004), determined that behavioral effects can account for up to $96.0 \%$ of the effects of toadfish on juvenile hard clams (Table 1).

Toadfish presence significantly reduced the total number of mobile crabs by almost an order of magnitude $\left(F_{1,6}=20.5 ; P=0.004\right.$; Fig. 3a). Repeatedmeasures ANOVA revealed that the interaction between toadfish and experimental day was not significant $\left(F_{5,30}=1.0 ; P=0.43\right)$. Experimental day also affected the total number of crabs that were mobile $\left(F_{5,30}=2.9\right.$; $P=0.03$; Fig. 3b). Specifically, slightly more crabs were mobile during the second than the final experimental day of the six-day trial. All other pair-wise comparisons of experimental days did not differ from each other. Toadfish presence also significantly reduced the proportion of visible crabs that were mobile by $67.9 \%$ $\left(F_{1,6}=71.8 ; P=0.0001 ;\right.$ Fig. 3c $)$. Finally, neither experimental day $\left(F_{5,30}=2.0 ; P=0.11\right)$ nor the interactions between toadfish and experimental day $\left(F_{5,30}\right.$ $=0.5 ; P=0.81)$ significantly affected the proportion of visible crabs that were mobile.

\section{DISCUSSION}

This study examined how habitat refugia influence the strength and direction of density-mediated indirect interactions (DMIIs) and trait-mediated indirect interactions (TMIIs) in oyster-reef communities. Toadfish indirectly benefited juvenile hard clams within the subsurface shell layers of the oyster reef that also provides shelter for mud crabs from toadfish. Thus toadfish increased clam survivorship even though they induced crabs to spend proportionally more time within the shell matrix in greater proximity to hard clams. This counterintuitive result can be partially explained by examining the effects of toadfish on mud crab behavior. In addition to inducing mud crabs to predominately utilize the protected subsurface layers of the oyster reef (Grabowski 2004), toadfish decrease mud crab mobility (Fig. 3). Reduced crab mobility within the shell layer should decrease encounters between mud crabs and clams and counteract increased proximity of mud crabs and juvenile hard clams as a consequence of toadfish inducing mud crabs to forage less on the surface of the reef. Partitioning the strength of DMIIs vs. TMIIs in this system determined that increased clam survival was a result of toadfish-induced changes in mud crab behavior rather than toadfish consumption of mud crabs. Toadfish indirectly benefit juvenile hard clams primarily by reducing mud crab foraging activity within the shell refuge even though the risk of predation by toadfish is largely reduced for mud crabs. This experiment illustrates that conceptual models of foodweb dynamics must carefully consider the pervasiveness and strength of behavioral mechanisms, especially within structured habitats that provide shelter from top predators. 
Increased crab-clam proximity coinciding with reduced crab foraging rates could be a consequence of how mud crabs locate their prey. Mud crabs utilize chemical cues to search for and locate their prey. $\mathrm{Bi}$ valves release scent plumes via their excurrent siphons, which extend upward towards the surface of the oyster reef. Crabs at the surface of the reef should encounter clam scent plumes more frequently than when buried within the reef, thereby increasing crab foraging efficiency. Predators that induce crabs to hide within the reef should further reduce crab detection of clams because increased habitat complexity reduces foraging efficiency by increasing the search time required to locate prey (Crowder and Cooper 1982). Therefore, intermediate predators that forage more effectively at the fringes of habitat patches may not forage as efficiently on prey within highly structured habitats when induced to hide within these patches even though they could be more proximal to their prey.

Species interactions often occur across ecological boundaries such as microhabitats, ecotones, and ecosystems, and can consequently influence community dynamics at several spatial scales. Predator risk influences habitat selection by prey, which often select less optimal foraging habitats to reduce predator encounter rates (Werner et al. 1983). In addition to influencing the behavior of their prey, predators can indirectly influence community dynamics within the refuge habitats in which their prey species relocate. When utilizing refugia to avoid predation, intermediate predators often refocus their foraging efforts on local prey within the sheltered habitats (Micheli 1997, Schmitz 1998, Schmitz et al. 2004). However, we found that movement of mud crabs into refuge habitats seemingly does not result in compensatory responses among prey resources (i.e., intermediate predators shifting from prey on the reef surface to subsurface prey resources) on oyster reefs. Initiation of prey switching within refuge habitats may necessitate that intermediate predators are capable of perceiving when their risk of being consumed is reduced (Grabowski 2004) or that intermediate predators can locate prey effectively when confined within the refuge habitat.

Within oyster-reef communities, toadfish generally release bivalve prey from mud crab predation. In addition, cascading effects of TMIIs on infaunal prey are much stronger than DMIIs initiated by toadfish consumption of mud crabs. Several of the limited number of studies that partition the relative strength of TMIIs and DMIIs suggest that behavior effects are greater than density effects (Huang and Sih 1991, Wissinger and McGrady 1993, Peacor and Werner 2001), though interactions among these effects can occur as a consequence of changes in behavior affecting resource levels (Werner and Peacor 2003). We may have overestimated the relative importance of TMIIs in this study because of the short experimental duration. If energy depletion eventually induces riskier behavior to locate
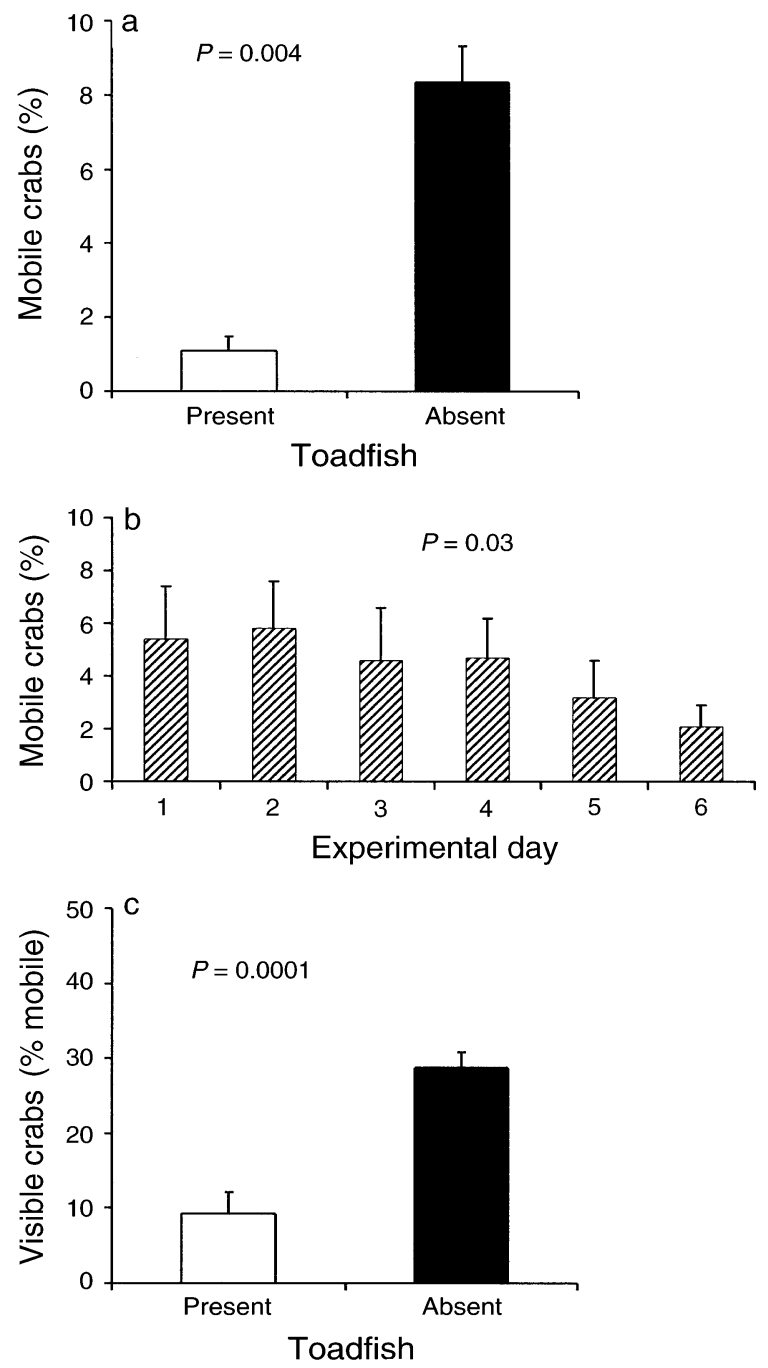

FIG. 3. Behavioral response of mud crabs to the presence of toadfish. Data are means and $1 \mathrm{SE}$; the $P$ values presented are the results of repeated-measures ANOVA. The effect of (a) toadfish ( $n=4$ replicates) and (b) experimental day $(n=$ 8 replicates) on the total percentage of mobile mud crabs in the enclosures. (c) The effect of toadfish on the percentage of mud crabs visible during observations that were moving ( $n=4$ replicates).

resources (Lima 1998), toadfish consumption of mud crabs and subsequent DMIIs on hard clams may be underestimated. However, mud crabs did consume prey in this study when toadfish are present, albeit at a lower rate than in their absence, so that it is unclear whether mud crabs are starving in the presence of toadfish. This study may have also overestimated the relative importance of TMIIs if mud crabs increase their clam consumption rates after a toadfish emigrates from a particular reef patch to compensate for recently reduced foraging rates. Yet toadfish are lie-and-wait predators that are territorial, so that compensatory responses would have to be very severe to counteract toadfishinduced behavioral effects that reduce crab foraging 
rates. In systems with seek-and-pursue predators, compensatory responses after non-lethal predatory encounters cease may dampen the relative importance of TMIIs. Future investigations of TMIIs should include partial-predator treatments to account for whether temporal variation in predatory presence influences the relative strength of TMIIs.

Refugia are a common facet of almost all ecosystems with both ecological and evolutionary significance for how we understand population dynamics and community structure (Huffaker 1958, Vermeij 1986, Pfister and Hay 1988, Caley and St John 1996). Relocation or aggregation of an intermediate predator species could initiate a trophic cascade within the recipient refuge habitat (Polis et al. 1997), illustrating the importance of considering how predators influence prey behavior, their distribution, and resultant community dynamics. In this study, toadfish benefit juvenile clams despite inducing crabs to primarily utilize a portion of the reef that is inaccessible to toadfish and in greater proximity to clams. Whether reduced foraging activity as a response to the presence of top predators is typical within refuge habitats will require a more exhaustive examination of how predator-induced behavioral responses affect interactions between intermediate predators and their prey. However, top predators should benefit basal prey in refuge habitats if intermediate predators remain vigilant because they are incapable of perceiving that the risk of being consumed by top predators is reduced or intermediate predators are less efficient foragers when confined to the refuge habitat. Partitioning the relative strength and direction of differing TMIIs and DMIIs within habitat refuges more definitively will require an understanding of how top predators affect intermediate prey density, habitat use, foraging activity, and encounter rates with their prey. Quantifying these processes is useful to determine whether aggregation of intermediate predators within refuge habitats to avoid top predators benefits or negatively impacts lower trophic levels.

\section{ACKNOWLEDGMENTS}

We would like to thank M. Dolan, R. Hughes, B. Tesh, D. Evans, and A. Whichard for assistance with the experiment. R. Hughes and T. Grosholz provided comments on the initial manuscript. Financial support was provided for this project by the NOAA-NERRS Graduate Research Fellowship Program (NOAA award number 97-040-NOC) and the North Carolina-Fishery Resource Grant Program (FRG Project number 97-EP-06).

\section{Literature Cited}

Arve, J. 1960. Preliminary report on attracting fish by oystershell planting in Chincoteague Bay, Maryland. Chesapeake Science 1:58-65.

Bahr, L. M., and W. P. Lanier. 1981. The ecology of intertidal oyster reefs of the South Atlantic Coast: a community profile. FWS/OBS-81/15. U.S. Fish and Wildlife Service, Washington, D.C., USA.

Caley, M. J., and J. St John. 1996. Refuge availability structures assemblages of tropical reef fishes. Journal of Animal Ecology 65:414-428.
Carpenter, S. R., J. F. Kitchell, and J. R. Hodgson. 1985. Cascading trophic interactions and lake productivity. BioScience 35:634-639.

Coen, L. D., M. W. Luckenbach, and D. L. Breitburg. 1999. The role of oyster reefs as essential fish habitat: a review of current knowledge and some new perspectives. American Fisheries Society Symposium 22:438-454.

Connell, J. H. 1980. Diversity and the coevolution of competitors, or the ghost of competition past. Oikos 35:131138.

Crowder, L. B., and W. E. Cooper. 1982. Habitat structural complexity and the interaction between bluegills and their prey. Ecology 63:1802-1813.

Day, R. W., and G. P. Quinn. 1989. Comparisons of treatments after an analysis of variance in ecology. Ecological Monographs 59:433-463.

Dill, L. M., M. R. Heithaus, and C. J. Walters. 2003. Behaviorally mediated indirect interactions in marine communities and their conservation implications. Ecology 84: 1151-1157.

Forrester, G. E. 1994. Influences of predatory fish on the drift dispersal and local density of stream insects. Ecology 75: $1208-1218$.

Grabowski, J. H. 2002. The influence of trophic interactions, habitat complexity, and landscape setting on community dynamics and restoration of oyster reefs. Dissertation. University of North Carolina, Chapel Hill, North Carolina, USA.

Grabowski, J. H. 2004. Habitat complexity disrupts predatorprey interactions but not the trophic cascade on oyster reefs. Ecology 85:995-1004.

Grabowski, J. H., and S. P. Powers. 2004. Habitat complexity mitigates trophic transfer on oyster reefs. Marine Ecology Progress Series 277:291-295.

Hairston, N. G., F. E. Smith, and L. B. Slobodkin. 1960. Community structure, population control, and competition. American Naturalist 94:421-425.

Huang, C., and A. Sih. 1991. Experimental studies on direct and indirect interactions in a three trophic-level stream system. Oecologia 85:530-536.

Huffaker, C. B. 1958. Experimental studies on predation: dispersion factors and predator-prey oscillations. Hilgardia 27:343-383.

Lenihan, H. S., C. H. Peterson, J. E. Byers, J. H. Grabowski, G. W. Thayer, and D. R. Colby. 2001. Cascading of habitat degradation: oyster reefs invaded by refugee fishes escaping stress. Ecological Applications 11:764-782.

Lima, S. L. 1998. Stress and decision making under the risk of predation: recent developments from behavioral, reproductive, and ecological perspectives. Advances in the Study of Behavior 27:215-290.

Luttbeg, B., L. Rowe, and M. Mangel. 2003. Prey state and experimental design affect relative size of trait- and density-mediated indirect effects. Ecology 84:1140-1150.

MacArthur, R., and R. Levins. 1967. The limiting similarity, convergence, and divergence of coexisting species. American Naturalist 101:377-385.

MacDonald, H. 1940. Animal associations of oysters at Beaufort, North Carolina. Thesis. Duke University, Durham, North Carolina, USA.

McDermott, J. J., and F. B. Flower. 1952. Preliminary studies of the common mud crabs on oyster beds of Delaware Bay. National Shellfisheries Association Convention Address 1952:47-50.

Menge, B. A. 1995. Indirect effects in marine rocky intertidal interaction webs: patterns and importance. Ecological Monographs 65:21-74.

Micheli, F. 1997. Effects of predator foraging behavior on patterns of prey mortality in marine soft bottoms. Ecological Monographs 67:203-224. 
Micheli, F., and C. H. Peterson. 1999. Estuarine vegetated habitats as corridors for predator movements. Conservation Biology 13:869-881.

Nakano, S., H. Miyasaka, and N. Kuhara. 1999. Terrestrialaquatic linkages: riparian arthropod inputs alter trophic cascades in a stream food web. Ecology 80:2435-2441.

Paine, R. T. 1966. Food web complexity and species diversity. American Naturalist 100:65-75.

Peacor, S. D., and E. E. Werner. 2001. The contribution of trait-mediated indirect effects to the net effects of a predator. Proceedings of the National Academy of Sciences (USA) 98:3904-3908.

Pfister, C. A., and M. E. Hay. 1988. Associational plant refuges: convergent patterns in marine and terrestrial communities result from differing mechanisms. Oecologia 77: 118-129.

Polis, G. A., W. B. Anderson, and R. D. Holt. 1997. Toward an integration of landscape and food web ecology: the dynamics of spatially subsidized food webs. Annual Review of Ecology and Systematics 28:289-316.

Power, M. E., W. J. Matthews, and A. J. Stewart. 1985. Grazing minnows, piscivorous bass, and stream algae: dynamics of a strong interaction. Ecology 66:1448-1456.

Schmitz, O. J. 1998. Direct and indirect effects of predation and predation risk in old-field interaction webs. American Naturalist 151:327-342.

Schmitz, O. J., V. Krivan, and O. Ovadia. 2004. Trophic cascades: the primacy of trait-mediated indirect interactions. Ecology Letters 7:153-163.

Schwartz, F. J., and B. W. Dutcher. 1963. Age, growth, and food of the oyster toadfish near Solomons, Maryland. Transactions of the American Fisheries Society 92:170173.

Seed, R. 1980. Predator-prey relationships between the mud crab, Panopeus herbstii, the blue crab Callinectes sapidus, and the Atlantic ribbed mussel Geukensia demissa. Estuarine, Coastal and Marine Science 2:445-448.

Shurin, J. B., E. T. Borer, E. W. Seabloom, K. Anderson, C. A. Blanchette, B. Broitman, S. D. Cooper, and B. S. Halpern. 2002. A cross-ecosystem comparison of the strength of trophic cascades. Ecology Letters 5:785-791.
Silliman, B. R., C. A. Layman, K. Geyer, and J. C. Zieman. 2004. Predation by the black-clawed mud crab, Panopeus herbstii, in mid-Atlantic salt marshes: further evidence for top-down control of marsh grass production. Estuaries 27: 188-196.

Strong, D. R. 1992. Are trophic cascades all wet? Differentiation and donor control in speciose ecosystems. Ecology 73:747-754.

Underwood, A. J. 1981. Techniques of analysis of variance in experimental marine biology and ecology. Oceanography and Marine Biology Annual Review 19:513-605.

Vermeij, G. J. 1986. Survival during biotic crises: the properties and evolutionary significance of refuges. Pages 231246 in D. K. Elliot, editor. Dynamics of extinction. John Wiley and Sons, New York, New York, USA.

Wells, H. W. 1961. The fauna of oyster beds, with special reference to the salinity factor. Ecological Monographs 31: 239-266.

Werner, E. E., and B. R. Anholt. 1996. Predator-induced behavioral indirect effects: consequences to competitive interactions in anuran larvae. Ecology 77:157-169.

Werner, E. E., J. F. Gilliam, D. J. Hall, and G. G. Mittelbach. 1983. An experimental test of the effects of predation risk on habitat use in fish. Ecology 64:1540-1548.

Werner, E. E., and S. D. Peacor. 2003. A review of traitmediated indirect interactions in ecological communities. Ecology 84:1083-1100.

Whetstone, J. M., and A. G. Eversole. 1978. Predation on hard clams, Mercenaria mercenaria, by mud crabs Panopeus herbstii. Proceedings of the National Shellfisheries Association 68:42-48.

Wilson, C. A., J. M. Dean, and R. Radtke. 1982. Age, growth rate, and feeding habits of the oyster toadfish, Opsanus tau (Linnaeus) in South Carolina. Journal of Experimental Marine Biology and Ecology 62:251-259.

Wissinger, S., and J. McGrady. 1993. Intraguild predation and competition between larval dragonflies: direct and indirect effects on shared prey. Ecology 74:207-218.

Wootton, J. T. 1993. Indirect effects and habitat use in an intertidal community: interaction chains and interaction modifications. American Naturalist 141:71-89. 